\title{
Irigation Monitoring Control Untuk Tanaman Hidroponik Dengan Metode $N f t$ Menggunakan Arduino Berbasis SMS Gateway
}

\author{
Wildan', Agus Romadhona², Ayu Hernita ${ }^{3}$ \\ Program Studi Teknik Informatika - STMIK Adhi Guna \\ Jl. Undata No.3, Lere, Kec. Palu Barat., Kota Palu, Sulawesi Tengah 94111 \\ E-mail: ${ }_{1 \text { wildan393@gmail.com }}^{2}$ agustmik_agp@yahoo.com, 3 ayunitha375@gmail.com
}

\begin{abstract}
Abstrak
Saat ini kandungan kadar PPM digunakan untuk menentukan kualitas tanaman hidroponik pertanian modern. Serta untuk mencukupi kebutuhan nutrisi tanaman hidroponik. Dihadapkan dengan masalah untuk mengetahui kandungan PPM tanaman yang biasanya berubah disebabkan oleh faktor alam. Masalah ini menyebabkan pemilik lahan tidak mengetahui perubahan kandungan nutrisi yang ada dalam bak penampungan. Sehingga timbul gagasan dalam penelitian ini untuk mengembangkan Prototype irigation monitoring control untuk tanaman hidroponik dengan menerapkan mikrokontroler didalamnya sebagai sistem kontrol otomatis. Metode pengumpulan data dalam melakukan penelitian ini peneliti mengamati secara langsung salah satu perkebunan hidroponik yang ada di kota palu. Metode yang digunakan metode eksperimental. Dengan sensor TDS meter untuk mengetahui kandungan nutrisi kemudian akan diproses oleh Mikrokontroler Arduino Uno. Dan menggunakan modul GSM SIM800L V2 yang berfungsi untuk mengirimkan informasi kandungan PPM dalam nutrisi. Dengan metode pengembangan prototype, agar peneliti mengetahui bagaimana sebuah sistem berjalan dengan baik. Berdasarkan hasil pengujian alat yang telah dilakukan, penerapan sensor TDS meter pada prototype dalam irigation monitoring control untuk tanaman hidroponik menggunakan Arduino uno dan sms gateway berjalan dengan baik. Ditunjukan dengan hasil pengujian yang telah dilakukan dengan menggunakan nutrisi sebagai objek yang dideteksi bahwa keberhasilan pengujian terhadap cara kerja alat berdasarkan hasil pembacaan sensor yang didapatkan adalah $83 \%$.
\end{abstract}

Kata Kunci : Arduino Uno, sensor TDS Meter, Modul GSM SIM800L V2, dan Nutrisi

\section{Abstract}

Currently PPM content is used to determine the quality of modern agricultural hydroponic plants. And to meet the nutritional needs of hydroponic plants. Faced with the problem to find out the PPM content of plants that usually changes due to natural factors. This problem causes landowners to not know the changes in the nutrient content in the reservoir. So that the idea arises in this research to develop prototype irigation monitoring control for hydroponic plants by applying a microcontroller in it as an automatic control system. Data collection methods in conducting this research the researchers directly observed one of the existing hydroponic plantations in the city of hammer. The method in this study uses an experimental method. With a TDS meter sensor to determine the nutrient content then it will be processed by Arduino Uno Microcontroller. And using the GSM SIM800L V2 module which functions to send information on PPM content in nutrition. With the prototype development method, so researchers know how a system works well. Based on the results of testing the equipment that has been done, the application of the TDS meter sensor on the prototype in irigation monitoring control for hydroponic plants using Arduino uno and sms gateways is going well. Shown by the results of tests that have been carried out using nutrition as an object that is detected that the success of testing the workings of the tool based on the sensor readings obtained was $83 \%$.

Keywords: Arduino Uno, Sensor TDS Meter, Modul GSM SIM800L V2, and Nutrition.

\section{PENDAHULUAN}

Hidroponik berasal dari bahasa Latin yang terdiri dari kata hydro yang berarti air dan kata ponos yang berarti kerja. Jadi definisi Hidroponik adalah pengerjaan atau pengelolaan air yang digunakan 
sebagai media tumbuh tanaman dan tempat akar tanaman mengambil unsur hara yang diperlukan. Umumnya media tanam yang digunakan bersifat poros, seperti pasir, arang sekam, batu apung, kerikil, rockwool [1].

Pada umumnya metode hidroponik yang dilakukan menggunakan media air, dimana kondisi air yang perlu diperhatikan adalah pasokan air, oksigen, nutrisi dan tingkat keasaman $(\mathrm{pH})$. Selain itu suhu dan kelembaban lingkungan harus terjaga dan sesuai dengan tanaman. Pengontrolan nutrisi, suhu air, volume air nutrisi, suhu lingkungan, $\mathrm{pH}$ dan kelembaban untuk sistem hidroponik masih dilakukan secara manual ataupun konvensional. Sehingga jika dilakukan satu persatu untuk pemeriksaan dan mengatur kondisi air untuk sistem hidroponik akan memakan banyak waktu dan tenaga. Untuk mempermudah dalam mengelola air nutrisi hidroponik, pada penelitian ini dibuatlah suatu sistem yang dapat memantau dan mengendalikan nutrisi, suhu dan tinggi pada air dalam pertanian hidroponik berbasis SMS GATEWAY[2].

Jika dilihat dari faktor perekonomian, sistem yang berbasis sms gateway ini sangat murah dibandingkan sistem yang menggunakan website. Perbandingan harga antara sistem yang berbasis sms gateway dan sistem yang berbasis website terbilang cukup jauh. Jika sistem yang menggunakan sms gateway hanya menghabiskan $\mathrm{Rp} 10.500$ perbulannya, dihitung dari biaya sms Rp 350,00 per sms dikali dengan sebulan (30 hari). Sementara sistem yang berbasis webasite membutuhkan biaya sebesar Rp 360.000 perbulannya, dikarenakan harga wifi berkisar sebesar Rp 360.000. Serta system ini dibuat agar tidak terkendala koneksi jaringan internet yang kadang buruk terpengaruh oleh cuaca.

Berangkat dari latar belakang di atas, untuk memecahkan permasalahan ini maka peneliti membuat sebuah sistem terintegrasi menggunakan Arduino sebagai pemroses, dengan beberapa perangkat sensor yaitu TDS sensor sebagai pengukur nilai ppm atau kepekatan konsentrasi air, dan sensor ketinggian air sebagai pengukur ketinggian air di dalam wadah penampungan. Air yang mengalir pada akar tanaman akan selalu terpantau dan terkontrol secara otomatis sehingga tanaman akan mendapatkan aliran air yang memiliki kualitas nutrisi sesuai dengan kebutuhan tanaman dan berdampak kepada optimalnya pertumbuhan tanaman. Begitu juga dengan para petani yang pekerjaannya akan menjadi lebih mudah dikarenakan mereka dapat memantau nilai PPM pada tanaman secara aktual, dan mereka tidak perlu melakukan penggantian air secara manual, karena semuanya telah dijalankan oleh system.

\section{LANDASAN TEORI}

\subsection{Mikrokontroler}

Komponen utama dari alat yang dirancang adalah Arduino uno. Arduino adalah perangkat elektronik atau papan rangkaian elektronik open - source yang di dalamnya terdapat komponen utama, yaitu sebuah chip mikrokontroler dengan jenis AVR dari perusahaan Atmel. Mikrokontroler itu sendiri adalah chip atau IC (Integrated circuit) yang bisa diprogram menggunakan komputer. Tujuan menanamkan program pada mikrokontroler adalah agar rangkaian elektronik dapat membaca input, memproses input tersebut kemudian menghasilkan output sesuai yang diinginkan. Jadi, mikrokontroler bertugas sebagai otak yang mengendalikan input, proses, dan output sebuah rangkaian elektronik. Salah satu tipe Arduino yang akan digunakan pada penelitian kali ini, yaitu Arduino Uno seperti pada Gambar 2.3 Arduino Uno adalah mikrokontroler berbasis ATmega 328P dengan Clock Speed 16Mhz dan Flash Memory $32 \mathrm{~KB}$. Dapat berjalan pada catu daya $7-12 \mathrm{~V}$. memiliki 14 pin digital input/output pada pin 013. 6 pin PWM pada pin 3, 5, 6, 9, 10, dan 11.6 pin analog input pada pin A0 - A5, sambungan USB, sambungan catu daya tambahan dan tombol pengaturan ulang[3].

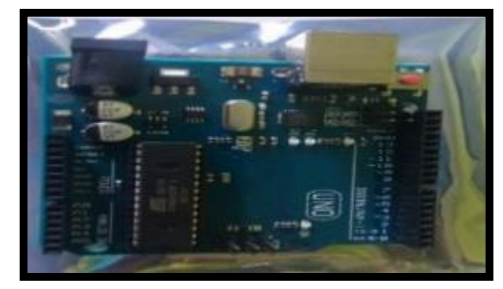

Gambar 1 Mikrokontroler

\section{2 $\operatorname{Sim} 800$ LV2}

SIM 800 adalah sebuah modem (Modulator/Demodulator). GSM/GPRS produk dari simcom (sanghai, China) yang bekerja di frekuensi $840-1900 \mathrm{MHz}$ yang memiliki beberapa fitur unggulan diantaranya GPRS multi slot class 12, mendukung kode GPRS CS-1 s.d CS-4, memiliki pin GPIO 
(General Purpose Input Output).ADC ( Analog to Digital converter) 10 bit, PWM (Pulse Width Modulation), radio FM, dsim 800an masih banyak yang lainnya. Salah satu implementasi modem SIM800 ini adalah unntuk membuat SMS CONTROLLER, sebuah pengendali peralatan elektronik berbasis SMS[3].

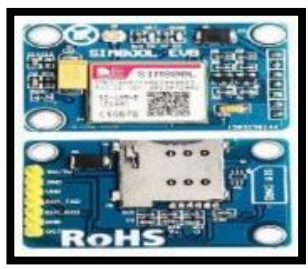

Gambar 2. Sim 800LV2

\subsection{TDS Meter}

TDS adalah singkatan dari "Total Disolved Solids" atau dalam bahasa indonesianya adalah "jumlah padatan terlarut". Jadi TDS meter memiliki pengertian "alat untuk mengukur jumlah padatan atau partikel terlarut didalam air ". Alat ini biasa digunakan untuk mengukur jumlah partikel terlarut pada air minum dan juga digunakan untuk mengukur kepekatan larutan nutrisi hidroponik atau dengan kata lain konsentrasi larutan nutrisi. Pengukuran nutrisi hidroponik adalah suatu hal yang mutlak dan sifatnya sangat penting. Sebab jika larutan tidak diukur, bisa jadi tanaman kekurangan nutrisi atau kelebihan yang akan menjadi racun yang dapat membunuh tanaman itu sendiri. Satuan yang digunakan pada TDS meter adalah ppm[4].

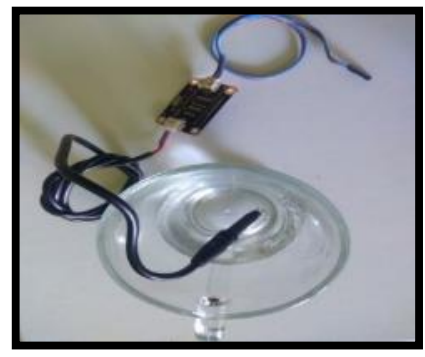

Gambar 3. TDS Meter

\subsection{Sensor ketinggian Air (Water Level)}

Sensor Air digunakan untuk mendeteksi tingkat zat yang bisa mengalir. Zat - zat yang dimaksud adalah seperti cairan, nutrisi, bahan butiran dan bubuk. Pengukuran tingkat ketinggian dapat dilakukan di dalam sebuah wadah atau juga diletakkan dalam sungai maupun danau. Pengukuran seperti itulah yang dapat digunakan sebagai penentu jumlah material di dalam wadah tertutup maupun dalam aliran terbuka[5].

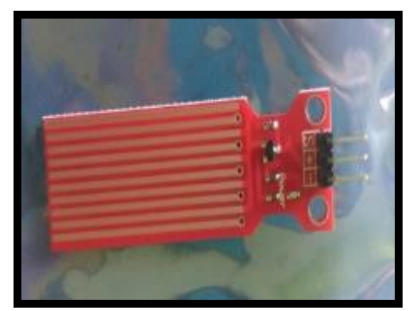

Gambar 4. Sensor ketinggian Air (Water Level)

\subsection{Relay}

Rangkaian Relay adalah rangkaian elektronika yang digunakan untuk mengendalikan sesuatu dari jarak jauh. Relay sendiri merupakan saklar magnetis paling sering digunakan pada setiap rangkaian elektronika. Dalam dunia elektronika, relay sangat berperan penting dalam suatu rangkaian beban arus tinggi dengan arus rendah[6],[7]. 


\subsection{Adaptor/ Power Supply}

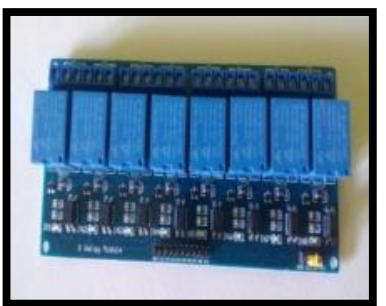

Gambar 5. Relay

Power Supply atau Adaptor merupakan rangkaian elektronika yang dapat menghasilkan energi listrik atau sebagai sumber energi untuk rangkaian elektronika lainnya. Sumber arus dari power supply adalah arus bolak - balik (AC) dari pembangkit listrik yang kemudian diubah menjadi arus searah (DC). Untuk dapat melakukan hal tersebut power supply memerlukan perangkat yang bisa mengubah arus AC menjadi DC[8],[9].

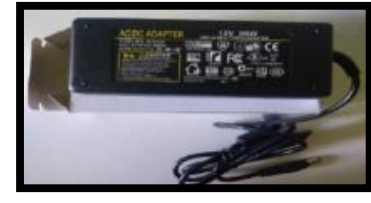

Gambar 6. Adaptor / Power Supply

\section{METODE PENELITIAN}

Penelitian dimulai dengan studi literatur yang berfungsi untuk mengumpulkan informasi berupa teori-teori pendukung yang akan digunakan dalam penelitian. Setelah itu dilanjutkan metode pengumpulan data berupa metode observasi untuk mengamati dan mencatat secara sistematik terhadap gejala yang tampak pada objek penelitian. Selanjutnya dilakukan tahap Analisa kebutuhan sistem, yang terdiri dari Analisa kebutuhan perangkat keras dan perangkat lunak. Berdasarkan hasil analisa kebutuhan sistem, dilakukan proses perancangan sistem yang melibatkan komponen perangkat keras dan perangkat lunak. Setelah selesai proses perancangan, maka akan dilanjutkan pada proses integrasi dan implementasi sistem. Tahap terakhir yang dilakukan adalah proses pengujian sistem, mulai dari pengujian sensorsensor, relay, dan SMS Gateway, hingga pengujian keseluruhan sistem.

\section{PERANCANGAN SISTEM}

Perancangan system yang akan dilakukan terdiri dari perancangan perangkat keras dan perangkat lunak.
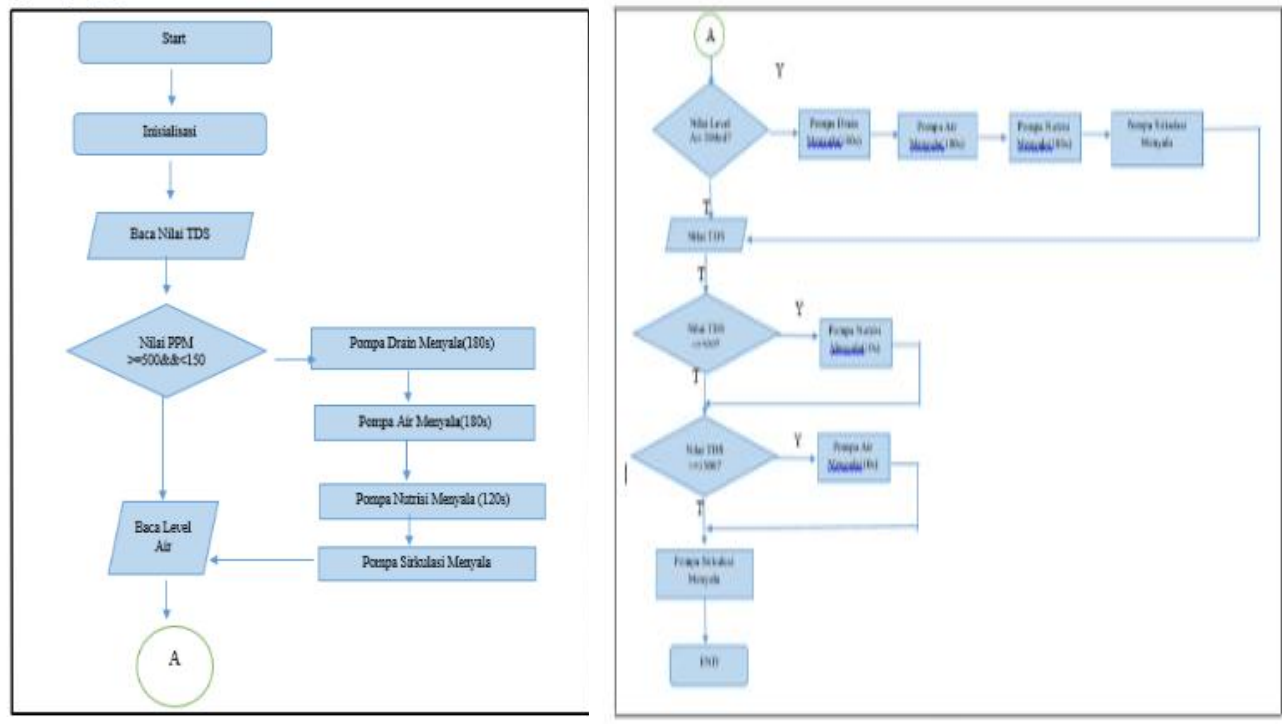

Gambar 7. Flowchart 
Perancangan perangkat keras terdiri dari perancangan komponen Arduino. Komponen yang ada pada Arduino antara lain, TDS meter, Waterlever, sms Gateway Dan relay. Perancangan perangkat lunak terdiri dari program sms gateway, program tds meter dan program waterlebvel yang terhubung menjadi satu bagian program. Secara umum perancangan system irigatin monitoring control pada tanaman hidroponik berbasis sms gateway diperlihatkan pada gambar 7 .

\subsection{Perancangan desain alat}

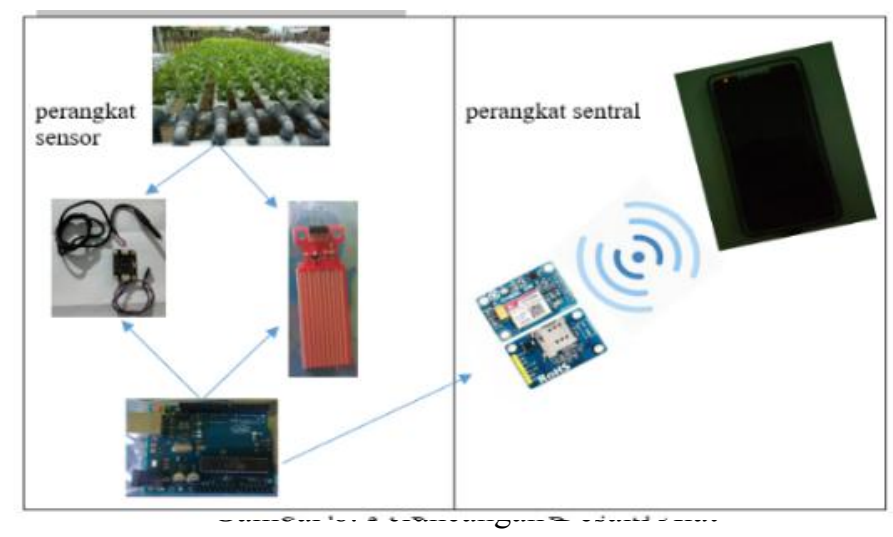

Seperti gambar 8 dijelaskan bahwa perangkat terbagi menjadi 2 bagian yaitu perangkat sensor dan perangkat sentral. Perangkat sensor terletak disekitar pengairan tanaman, sedangkan perangkat sentral diletakan didekat sistem atau alat hidroponik. Perangkat sensor disini terdiri dari Mikrokontroler Arduino Uno, Sensor Tds Meter, Sensor ketinggian air, beserta 3 Wiper yang bertugas sebagai penyalur air baku, penyalur Nutrisi, dan saluran pembuangan air dari penampungan yang sudah tidak bagus kadar PPMnya, serta terdapat 1 buah pompa yang menyalurkan air dari bak penampungan ke akar-akar tanaman.

\section{PENGUJIAN DAN PEMBAHASAN}

\subsection{Pemasangan sensor TDS meter.}

Pada prototype ini pemasangan sensor tds diletakkan pada bagian tengah kotak penampungan yang berbentuk persegi putih. Sementara papan shieldnya terletak dibagian belakang tepi atas papan triplek. Pemasangan sensor tds dapat dilihat pada gambar 9.

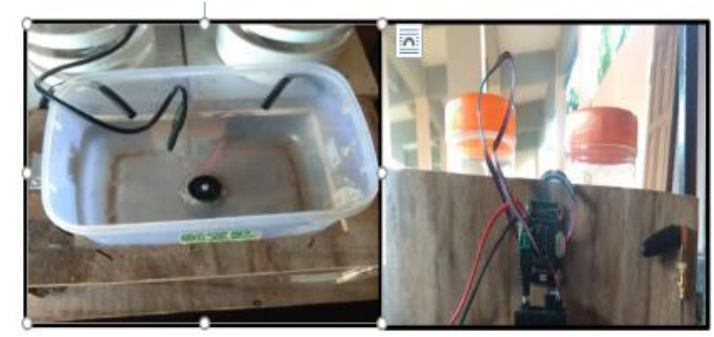

Gambar 9. Pemasangan Sensor TDS Meter

\subsection{Pemasangan Mikrokontroler}

Pada prototype ini pemasangan mikrokontroler arduino uno diletakkan dibagian tengah papan triplek. Arduino uno sudah dirangkaikan dengan shield Arduino. Pemasangan mikrokontroler Arduino uno dapat dilihat pada gambar 10. 


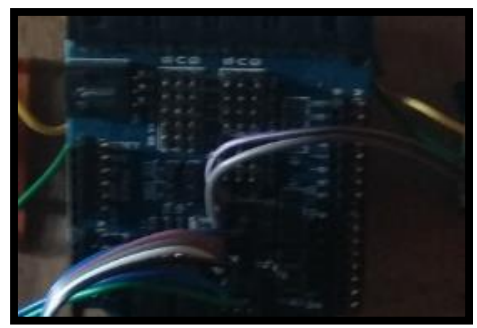

Gambar 10. Pemasangan Mikrokontroler

4.3 Pemasangan Modul SIM800L V2

Pada prototype ini pemasangan modul SIM800L V2 diletakkan disisi pinggir sebelah kanan pada papan tripel berdekatan dengan Arduino uno. Pemasangan SIM800L V2 dapat dilihat pada gambar 11.

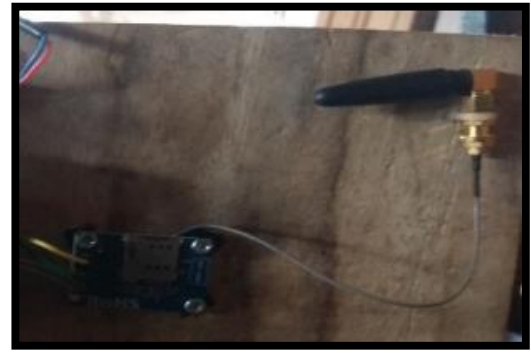

Gambar 11. Pemasangan Modul SIM800L V2

\subsection{Pemasangan Driver Relay}

Pada prototype ini pemasangan mikrokontroler driver relay diletakan pada sisi bagian bawah papan tripel. Tepat berada dibawah mikrokontroler Arduino uno. Pemasangan driver relay dapat dilihat pada gambar 12 .

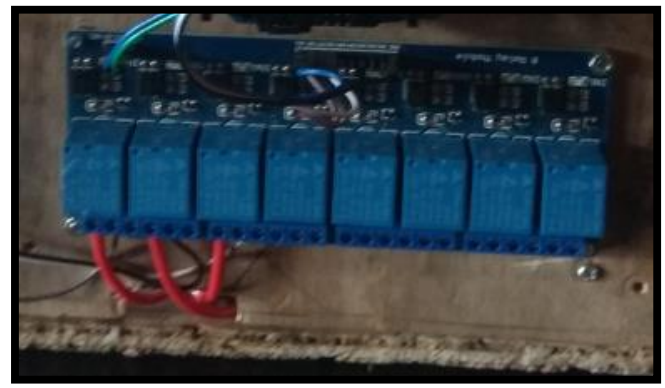

Gambar 12. Pemasangan Driver Relay

\subsection{Pemasangan Water Level}

Pada prototype ini pemasangan water level diletakkan pada sisi kotak putih tempat penampungan campuran. Pemasangan water level dapat dilihat pada gambar 13.

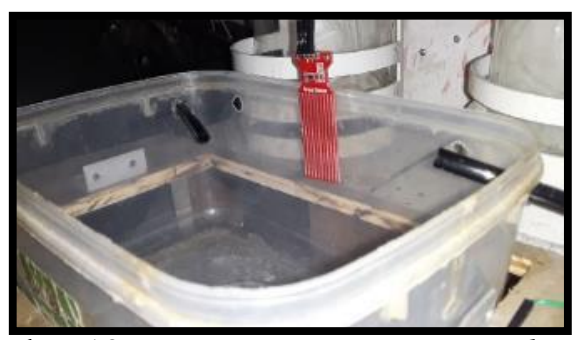

Gambar 13. Pemasangan Water Level 


\subsection{Pemasangan Motor Washper}

Pada prototype ini ketiga motor washper diletakkan pada masing-masing tabung penampungan air, penampungan nutrisi dan penampungan campuran. Motor washper diletakkan pada bagian bawah disetiap penampungan dengan cara membuat lobang untuk setiap ukuran motor. Dan mengelemnya kembali jika motor wasper sudah dimasukan dibagian tengah-tengah penampungan. Pemasangan motor wasper dapat dilihat pada gambar 14 .

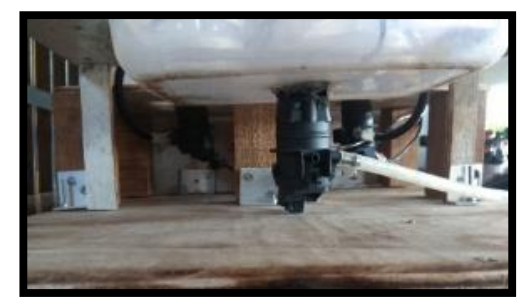

Gambar 14. Pemasangan Motor Washper

\subsection{Pengujian}

4.7.1 Pengujian Pada PPM Rendah

Dalam pengujian ini ketinggian campuran berapa pada 0-10 $\mathrm{cm}$ dan akan terkirim perintah sms kepada pemilik tanaman/petani.

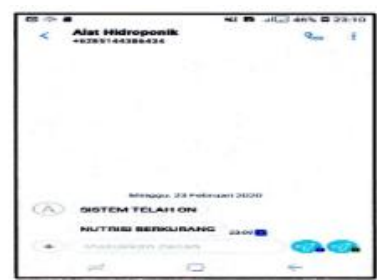

Gambar 15. Pengujian Pada PPM Rendah

\subsubsection{Pengujian Arduino Terhadap Modul GSM SIM 800LV2}

Pengujian Arduino terhadap modul GSM SIM800LV2 dilakukan dengan menghubungkan Arduino ke modul SIM800LV2. Setelah terhubung kemudian modul SIM800LV2 akan otomatis mencari jaringan GSM, agar dapat mengirim sms notifikasi ke nomor tujuan

\begin{tabular}{|c|c|c|c|}
\hline No & $\begin{array}{c}\text { Modul GSM SIM 800L } \\
\text { Terhubung Ke Arduino }\end{array}$ & Status Jaringan & $\begin{array}{c}\text { Status } \\
\text { Pengiriman }\end{array}$ \\
\hline 1 & $\checkmark$ & $\checkmark$ & SMS Terkirim \\
\hline 2 & $\checkmark$ & $\checkmark$ & SMS Terkirim \\
\hline 3 & $\checkmark$ & $\checkmark$ & SMS Terkirim \\
\hline 4 & $\checkmark$ & $\checkmark$ & SMS Terkirim \\
\hline 5 & $\checkmark$ & $\checkmark$ & SMS Terkirim \\
\hline
\end{tabular}

Gambar 16. Pengujian Arduino Terhadap Modul GSM SIM 800LV2

\subsubsection{Pengujian Arduino Terhadap Pompa Waspher}

Pengujian ini dilakukan sebanyak tiga kali dengan cara begantian dalam wadah penampungan yang telah dibuat

\begin{tabular}{|c|c|c|c|}
\hline No & Pembacaan Sensor & Ketinggian Campuran & Keterangan \\
\hline 1 & $10 \mathrm{~cm}$ & $\checkmark$ & Ppm Rendah \\
\hline 2 & $15 \mathrm{~cm}$ & $\checkmark$ & Ppm Normal \\
\hline 3 & $18 \mathrm{~cm}$ & $\mathrm{x}$ & Ppm Eror \\
\hline 4 & $5 \mathrm{~cm}$ & $\checkmark$ & Ppm rendah \\
\hline 5 & $12 \mathrm{~cm}$ & $\checkmark$ & Ppm Normal \\
\hline 6 & $17 \mathrm{~cm}$ & $\mathrm{x}$ & Ppm Eror \\
\hline
\end{tabular}

Gambar 17 Pengujian Arduino Terhadap Pompa Waspher 


\subsubsection{Pengujian Terhadap Keseluruhan Alat}

Pengujian dilakukan sebanyak 4 kali, dengan cara mengubah ketinggian air dan campuran pada wadah penampungan yang telah dibuat.

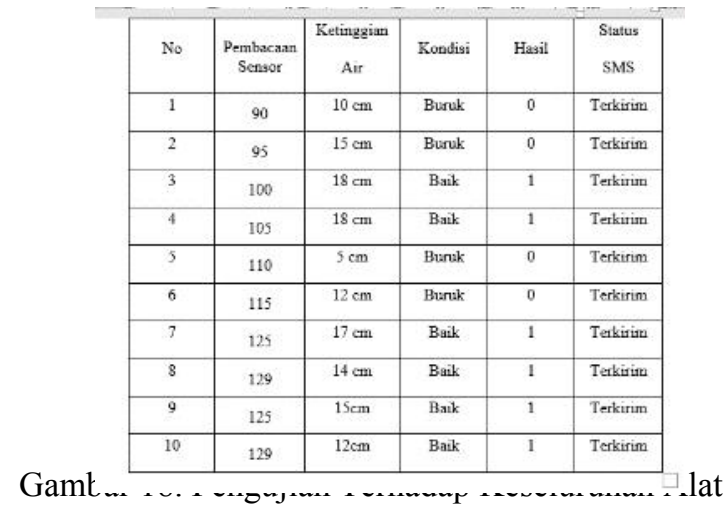

\section{KESIMPULAN}

Berdasarkan hasil analisis data dan pengujian alat disimpulkan bahwa alat tersebut mampu bekerja dengan baik serta dapat memberikan informasi tentang keadaan kadar PPM tanaman sehingga pemilik/petani dapat memantau kadar PPM tanaman hidroponik.

Serta penerapan TDS Meter pada prototype Irigation Monitoring Control untuk tanaman hidroponik berbasis Arduino uno dan sms gateway berjalan dengan baik. Ditunjukkan dengan hasil pengujian yang telah dilakukan dengan menggunakan nutrisi sebagai objek yang dideteksi. Bahwa alat dapat bekerja sesuai dengan hasil pembacaan sensor.

\section{SARAN}

Berdasarkan dari hasil kesimpulan, maka peneliti memberi saran :

1. Diharapkan system prototype Irigation Monitoring Control Untuk Tanaman Hidroponik ini dapat dikembangkan lebih lanjut dengan bentuk penanganan yang lebih kompleks lagi.

2. Dapat diterapkan pada tempat yang sesungguhnya sehingga bukan dalam bentuk prototype lagi.

3. Pengembangan sumber daya cadangan yang lebih baik lagi.

\section{DAFTAR PUSTAKA}

[1] Lingga, P. 1999. Hidroponik Bercocok Tanam Tanpa Tanah. Penebar Swadaya. Jakarta. Hal.99

[2] Edi Kresnha, Priadhana. Dkk. 2019. Automasi Hidroponik Indoor Sistem Wick dengan Pengaturan Penyinaran Menggunakan Growing Lights dan Pemberitahuan Nutrisi Berbasis SMS Gateway. Jurnal Kumparan Fisika.

[3] Khabib Allin, Nurul. 2019. Sistem Pengendalian Suhu Air Nutrisi Hidroponik Nft (Nutrient Film Tehnique) Menggunakan Sensor Suhu Dan Sms Gateway Berbasis Arduino. JURNAL ELEKTRONIKA DAN KOMPUTER.

[4] Chadirin, Y. 2007. Teknologi Greenhouse dan Hidroponik., JURNAL ELEKTRONIKA DAN KOMPUTER.

[5] Rausan Fikri dkk, 2015. Rancangan Bangun Sistem Monitoring Ketinggian Air Permukaan Air Menggunakan Mikrokontroler ATMEGA-328P Berbasis Web Service. 
[6] Sugiri Arnawa I G.P., Raka Agung I G.A.P., (2015), Prototipe Monitoring Ketinggian Permukaan Air Bendungan Melalui Media Sosial Twitter Berbasis Mikrokontroler ATMEGA.

[7] Putra, Yuga Hadfridar, DKK. 2018. Sistem Pemantauan Dan Pengendalian Nutrisi, Suhu, Dan Tinggi Air Pada Pertanian Hidroponik Berbasis Website. Jurnal Coding, Sistem Komputer Untan. Hal. 128

[8] Putranto, Tommy Dwi, DKK. 2016. Jurnal Rancangan bangunan system otomatis pemberian nutrisis dan pencahayaan untuk tahap penyemaian benih selada pada perkebunan Surabaya Hidroponik.

[9] Putranto, Tommy Dwi, DKK. 2016. Jurnal Rancangan bangunan system otomatis pemberian nutrisi dan pencahayaan untuk tahap penyemaian benih selada pada perkebunan Surabaya hidroponik.

[10] Cahyono, B. 2014. Teknik Budidaya Daya dan Analisis Usaha Tani Selada. CV.Aneka Ilmu. Semarang. hal. 114 